\title{
Oxytocin in the Medial Amygdala is Essential for Social Recognition in the Mouse
}

\author{
Jennifer N. Ferguson, J. Matthew Aldag, Thomas R. Insel, and Larry J. Young \\ Center for Behavioral Neuroscience and the Department of Psychiatry and Behavioral Sciences, Emory University, \\ Atlanta, Georgia 30322
}

\begin{abstract}
Oxytocin (OT) knock-out mice fail to recognize familiar conspecifics after repeated social exposures, despite normal olfactory and spatial learning abilities. OT treatment fully restores social recognition. Here we demonstrate that OT acts in the medial amygdala during the initial exposure to facilitate social recognition. OT given before, but not after, the initial encounter restores social recognition in OT knock-out mice. Using c-Fos immunoreactivity (Fos-IR) as a marker of neuronal activation in this initial encounter, we found similar neuronal activation in the wild-type (WT) and OT knock-out mouse in olfactory bulbs, piriform cortex, cortical amygdala, and the lateral septum. Wildtype, but not OT knock-out mice exhibited an induction of
\end{abstract}

Fos-IR in the medial amygdala. Projections sites of the medial amygdala also failed to show a Fos-IR induction in the OT knock-out mice. OT knock-out, but not WT, mice showed dramatic increases in Fos-IR in the somatosensory cortex and the hippocampus, suggesting alternative processing of social cues in these animals. With site-specific injections of OT and an OT antagonist, we demonstrate that OT receptor activation in the medial amygdala is both necessary and sufficient for social recognition in the mouse.

Key words: oxytocin; social memory; social recognition; olfaction; pheromone; medial amygdala
Social recognition forms the foundation on which all social relationships are built. Across species, social memories are required for kin recognition and for the establishment of dominant-subordinate relationships. In rodents, enduring social memories are a component of a variety of complex social and reproductive processes, including pair bond formation in monogamous species (Demas et al., 1997) and selective pregnancy termination in mice (Kaba et al., 1989; Keverne, 1998). Rats and mice also display short-term memories of recently encountered individuals, which decay in $\sim 1$ hr (Gheusi et al., 1994; Popik and van Ree, 1998). In the laboratory, social recognition is measured by a decline in the amount of time spent investigating the same individual during repeated pairings (Thor and Holloway, 1981).

The neuropeptide oxytocin (OT) has been implicated in a number of social behaviors, including maternal care, affiliation, and social attachment (Carter et al., 1992; Insel, 1992, 1997). In sheep, OT acting in the olfactory bulb is involved in the long-term olfactory memory of the newborn lamb (Keverne and Kendrick, 1992; Da Costa et al., 1996). OT knock-out (OTKO) mice fail to display social recognition despite apparently normal olfactory and spatial learning abilities (Ferguson et al., 2000). Because social memory in OTKO mice is rescued by a single intracerebroventricular infusion of OT, the recognition deficit appears to be attributable to the absence of OT in adulthood and not to developmental effects of the null mutation (Ferguson et al., 2000). The OTKO mouse thus provides an excellent opportunity to investi-

Received May 23, 2001; revised July 23, 2001; accepted Aug. 8, 2001.

This research was funded by a grant from the National Alliance for Autism Research (L.J.Y.), the National Institute of Mental Health Grant MH56897, and the National Science Foundation Science and Technology Center program Grant IBN9876754 (T.R.I.).

Correspondence should be addressed to Larry J. Young, Center for Behavioral Neuroscience, Yerkes Research Center, 954 Gatewood Road, Emory University, Atlanta GA 30322. E-mail: lyoun03@emory.edu.

Copyright (ㄷ) 2001 Society for Neuroscience $0270-6474 / 01 / 218278-08 \$ 15.00 / 0$ gate the neural mechanisms by which OT modulates social and mnemonic processes.

Here we investigate the temporal and neuroanatomical mechanisms of OT-facilitated social recognition. We compare OT infusions given just before or just after the initial exposure to determine whether OT is essential for the normal acquisition and processing of social cues or for the recall of this information. Then, to investigate the neural mechanisms underlying the memory deficit, we compare neuronal activation in wild-type (WT) and OTKO mice by quantifying Fos immunoreactivity (Fos-IR) after a brief social exposure. Finally, based on the differences in regional brain activity, we use site-specific injections of OT and an OT antagonist (OTA) to investigate the relative role of the olfactory bulb and the medial amygdala. These results demonstrate that OT receptor activation in the medial amygdala is essential for the acquisition of social memories.

\section{MATERIALS AND METHODS}

Animals. All OTKO and WT mice used in the study were derived from heterozygous matings of mice descended from the recombinant hybrid mouse originally constructed from $129 \mathrm{SvEv}$ and C57BL/6J background strains (Nishimori et al., 1996). The genotype of all individuals was confirmed using a PCR-based genotyping protocol, with DNA purified from tail clips of 7- to 10-d-old pups. A single $5^{\prime}$ primer common to both the WT and OTKO allele and two genotype-specific $3^{\prime}$ primers were used for the amplification. The WT-specific $3^{\prime}$ primer was complimentary to a sequence in the first exon that was deleted in the OTKO allele, and the 3' OTKO specific primer was complimentary to a sequence in the phosphoglycerate kinase promoter of the OTKO allele. Pups were weaned at $21 \mathrm{~d}$ and placed in same-sex group housing. All mice were housed under standard vivarium conditions $\left(23^{\circ} \mathrm{C}\right.$, food and water provided ad libitum). Lights came on at 7:00 A.M. and went off at 7:00 P.M., with all tests and procedures performed during the light phase, between 1100 A.M. and 4:00P.M.. Adult ( $>50 \mathrm{~d}$ ), group-housed ovariectomized female heterozygous mice were used as stimulus animals for the both the social memory and social exposure trials.

Social recognition tests. At age 40-50 d, mice were transferred from group to individual housing for $7-10 \mathrm{~d}$ to permit establishment of a 
home-cage territory. To minimize sexual behavior during the experimental trials, animals were habituated to ovariectomized, stimulus females several times per day for $4-5 \mathrm{~d}$ before the first behavioral tests. Subjects were also habituated to the behavioral testing room 12-18 hr immediately before experimentation. Each trial began when an ovariectomized stimulus mouse was introduced into the home cage of one subject ( $n=12$ per genotype) for a 5 min interaction. At the end of the 5 min trial, the stimulus animal was removed and returned to an individual holding cage. After a $30 \mathrm{~min}$ interexposure interval, another stimulus animal was introduced to each subject. During "different female" trials, the stimulus animal introduced during the second trial was novel, whereas, during "same female" or recognition trials, the same stimulus animal was used during both the first and second encounter. All behavior was recorded on videotape and subsequently scored by a trained rater blind to the experimental conditions, using a computer-assisted data acquisition system. Across all trials, investigation was defined as direct, active, olfactory exploration of the stimulus female by the subject male. In general it consisted of nosing and sniffing of the head and anogenital regions, as well as close following and pursuit. Grooming, aggressive posturing, and sexual behaviors including mounting were not included in measures of investigation (Thor and Holloway, 1982; Dantzer et al., 1987; Winslow and Camacho, 1995).

Social exposure for c-Fos immunoreactivity. OTKO and WT males were divided into socially exposed (EXPOSED) and socially unexposed (UNEXPOSED) groups ( $N=6$ per genotype and experimental condition). All animals were individually housed for $7-10 \mathrm{~d}$ before experimentation and isolated from female pheromones for $48 \mathrm{hr}$ immediately before testing. At the beginning of the trial, each of the 12 animals assigned to the EXPOSED group was presented in his home cage with an ovariectomized female for $90 \mathrm{sec}$. All interactions were videotaped and later scored by a trained observer. After the $90 \mathrm{sec}$ exposure, the stimulus female was removed and the experimental subject left undisturbed for 1 hr. All animals were then anesthetized with ketamine and transcardially perfused with cold PBS followed by cold $4 \%$ paraformaldehyde, $\mathrm{pH}$ 7.4. The 12 animals assigned to the UNEXPOSED group were not provided with a social experience before tissue collection and were left undisturbed in their home cages until they were anesthetized for transcardial perfusion. The perfused brains were subsequently removed for immunocytochemical processing.

Immunocytochemistry. The 24 perfused brains of the animals from all four experimental groups were placed in fresh $4 \%$ paraformaldehyde for $24 \mathrm{hr}$ and then transferred to $30 \%$ sucrose and stored at $4^{\circ} \mathrm{C}$. Using a sliding microtome, $40 \mu \mathrm{m}$ coronal sections were cut from the rostral pole of the olfactory bulb through the caudal extent of the amygdala. Freefloating, alternating sections were dipped in $1.5 \% \mathrm{H}_{2} \mathrm{O}_{2}$, washed three times in KPBS, and incubated in $0.3 \%$ Triton X-100, $0.3 \%$ normal goat serum, 1\% BSA, KPBS, and the Fos primary (1:10,000 rabbit polyclonal antiserum; catalog \#sc-52; Santa Cruz Biotechnology, Santa Cruz, CA) for $1 \mathrm{hr}$ at room temperature and $48 \mathrm{hr}$ at $4^{\circ} \mathrm{C}$. Sections were then washed twice for $5 \mathrm{~min}$ in KPBS and incubated with biotinylated goat anti-rabbit secondary for $1 \mathrm{hr}$ at room temperature. Then the sections were washed four times in KPBS, incubated for $1 \mathrm{hr}$ at room temperature in avidinbiotin complex, washed four more times in KPBS, and then reacted with DAB solution for $4 \mathrm{~min}$. The sections were washed four final times and then mounted on Fisher-plus slides, air-dried, and coverslipped. Slides were coded so that the raters had no knowledge of treatment condition or genotype. A high-magnification image $(200 \times)$ of each section was captured and analyzed using NIH Image software. The total number of stained nuclei in three sections from both the left and right hemispheres from each subject were counted, averaged, and divided by the total area to derive a value for the total number of stained nuclei per square millimeter of tissue.

Intracerebroventricular injections. Male OTKO mice $(N=12)$ were fitted with intraventricular cannulas. Under ketamine and xylazine anesthesia, in a stereotaxic apparatus, a $1 \mathrm{~mm}$ midline incision across the top of the skull was made, the periosteum was removed, and a $1 \mathrm{~mm}$ hole located $1.1 \mathrm{~mm}$ lateral to bregma was drilled. A 26 gauge stainless-steel indwelling cannula (Plastics One, Roanoke, VA) was implanted $0.26 \mathrm{~mm}$ below the skull surface into the lateral ventricle. The cannula was secured to the skull with dental cement, and a dummy cannula was inserted to maintain patency. Injections were made using a 33 gauge stainless-steel injector attached to PE-10 tubing fitted to a $10 \mu \mathrm{l}$ Hamilton syringe. Injections began 3-4 d after mice recovered from surgery. OT ( 0 or $1 \mathrm{ng}$ in $4 \mu \mathrm{l}$ of artificial CSF) was delivered to awake, restrained, mice over 60-90 sec. During the "before" trials, subjects were injected with either OT or CSF 10 min before the first behavioral encounter. During the "after" trials, subjects were injected with either OT or CSF $10 \mathrm{~min}$ after the first $5 \mathrm{~min}$ social interaction. After the $30 \mathrm{~min}$ intertrial interval, each subject was reintroduced to the same stimulus female, and the duration of olfactory investigation was quantified as above. Each subject received all treatments with a minimum of $72 \mathrm{hr}$ between administrations. At the completion of the testing series, a $4 \mu \mathrm{l}$ volume of $10 \%$ India ink in CSF was injected into the brain to verify cannula placement.

Intracerebroventricular OT dose-response curve. OTKO males $(N=8)$ were cannulated as described above and received intracerebroventricular injections of OT $(1000,10,1,0.1,0,0.01$, or $0 \mathrm{pg}$ dissolved in $4 \mu \mathrm{l}$ of CSF), 10 min before the first 5 min stimulus exposure. The order in which doses were administered was pseudorandomized, and a given individual did not receive consecutive injections more than once every 72 hr. Injections of CSF were interspersed among peptide injections to confirm a constant baseline response pattern.

Site-specific injections. WT and OTKO males $(N=14$ per genotype) were prepared for cannulation as described above. Mice were fitted with two bilateral cannulas directed at the olfactory bulbs and the medial amygdala. For the olfactory bulbs, 26 gauge bilateral cannulas (center to center distance, $1.0 \mathrm{~mm}$ ) were placed $1 \mathrm{~mm}$ beneath the surface of the skull, $0.5 \mathrm{~mm}$ lateral to the midline in the center of each bulb. For the medial amygdala, 24 gauge cannulas (center to center $5.0 \mathrm{~mm}$ ) were placed at a depth of $4.5 \mathrm{~mm}$ at $1.8 \mathrm{~mm}$ posterior and $2.5 \mathrm{~mm}$ lateral to bregma. Injections were made using bilateral 33 gauge stainless steel injectors attached to PE-10 tubing fitted to a $1 \mu$ l Hamilton syringe. Injections began 5-7 d after surgical recovery, and in all cases injections were bilateral and made $10 \mathrm{~min}$ before the first $5 \mathrm{~min}$ stimulus exposure. OTKO males received $0.5 \mu \mathrm{l}$ injections of either CSF or $0.1 \mathrm{pg}$ of OT, the highest dose determined to be ineffective in the ventricles. WT males received $0.5 \mu \mathrm{l}$ injections of either CSF or ornithine vasotocin ( $0.01 \mathrm{ng})$, an oxytocin antagonist (Peninsula Laboratories, Belmont, CA). The dose of the antagonist is 100 -fold lower than a dose shown to be only moderately effective in the ventricles (Ferguson et al., 2000). After the 30 min intertrial interval, each subject received a second 5 min exposure to the same stimulus female, and the duration of olfactory investigation was measured as described above. A given individual did not receive consecutive injections more than once every $72 \mathrm{hr}$ and received a single bilateral injection into either the bulbs or into the amygdala on a given day. Using a counterbalanced design, subjects received peptide and CSF injections into both neuroanatomical areas. After the final injections, cannula placement was verified. Subjects were deeply anesthetized using ketamine and xylazine, and a $0.5 \mu \mathrm{l}$ volume of $10 \%$ India ink in CSF was injected unilaterally into the olfactory bulb $(\mathrm{OB})$ and the medial nucleus of the amygdala $(\mathrm{MeA})$. We injected $0.5 \mu \mathrm{l}\left(250 \mathrm{pg}\right.$ of ${ }^{125} \mathrm{I}$-labeled $\mathrm{D}\left(\mathrm{CH}_{2}\right)^{5}\left[\mathrm{Tyr}(\mathrm{Me})_{2}, \mathrm{Tyr}^{9} \mathrm{NH}_{2}\right]$ of ornithine vasotocin (NEN, Boston, $\mathrm{MA}$ ) into the uninjected side of the $\mathrm{OB}$ and $\mathrm{MeA}, 10-15$ min later subjects were rapidly decapitated, and brain tissue was collected. Three sets of adjacent $20 \mu \mathrm{m}$ sections were thaw-mounted on slides. One set was stained with cresyl violet for visualization of cannula tracks. A second set was air dried before exposure to x-ray film to determine the spread of OTA after injection. The third set was washed for $1 \mathrm{hr}$ in $50 \mathrm{~mm}$ Tris and $100 \mathrm{~mm} \mathrm{MgCl}{ }_{2}, \mathrm{pH} 7.4$, to determine the field of OT receptors occupied by the injection. Both sets of slides were exposed to Biomax MR film (Kodak, Rochester, NY) for $48 \mathrm{hr}$. One OTKO subject was dropped from the study because of improper cannula placement, and one additional OTKO was dropped because of premature cannula loss. Three WT subjects were also lost from the study, one as a consequence of illness, and two others whose cannulas became clogged during the testing process.

Data analysis. The effect of genotype or treatment condition on social recognition was analyzed using Student's paired $t$ tests comparing the duration of investigation during the first and second social exposures. For presentation purposes, all raw behavioral data were converted to ratios of the time spent by each subject on olfactory investigation during the second trial as compared with the time spent during the first trial (Perio et al., 1989). Using these derived, relative duration of investigation (RDI) ratios, values $<0.5$ are typically indicative that the subject recognizes, or considers familiar, the stimulus animal presented during the second trial, whereas values close to 1 indicate that the subject considers the animal with whom he is interacting during that second encounter to be novel, or unfamiliar. These same ratios were also used to compare the influence of treatment condition across repeated trials within the same subjects in the dose-response and the before-after injection studies, using repeated measures, fixed factor ANOVAs. The number of c-Fos 


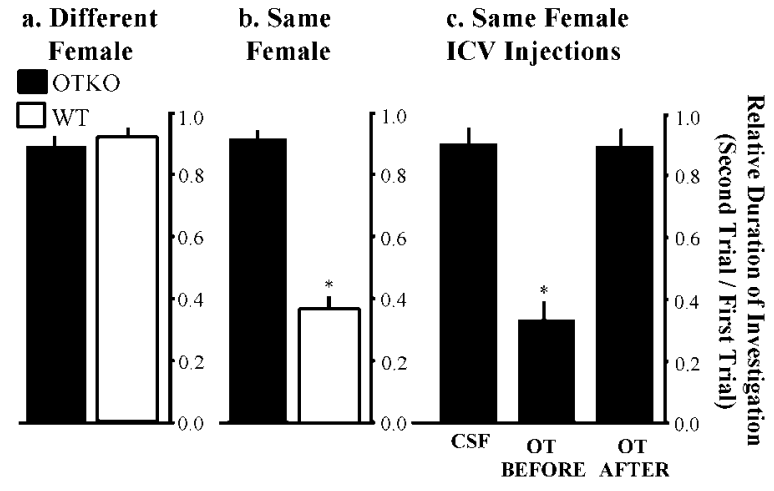

Figure 1. The social recognition deficit and its rescue by intracerebroventricular injections of OT. $a$, Different female trials: male mice were exposed to two novel ovariectomized stimulus females for 5 min each. After an interexposure interval of $30 \mathrm{~min}$, a novel female was paired with each male. The data are presented as the RDI \pm SEM. Neither OTKO nor WT males showed a significant decline in the amount of time spent investigating the females presented during the second trial. $b$, Same female trials: after the initial 5 min social encounter and a $30 \mathrm{~min}$ interexposure interval, each male was paired with the same female to whom he had been previously exposed. $c$, Intracerebroventricular injections of OT. Each male received three injections, given in random order: CSF, $1.0 \mathrm{ng}$ of OT administered $10 \mathrm{~min}$ before, and $1.0 \mathrm{ng}$ of OT administered $10 \mathrm{~min}$ after the first social exposure. Asterisks denote social recognition, measured as a decline in the duration of investigation during the second trial $(p<0.05)$.

cells per square millimeter was compared across both genotype and exposure conditions using a two-factor ANOVA. If either significant main effects or interaction effects were detected, an appropriate post hoc Newman-Keuls test comparison was used to measure individual treatment group differences. In all tests, $p<0.05$ was accepted as significant.

\section{RESULTS}

\section{Behavior}

A male mouse in his home cage, presented with an unfamiliar, ovariectomized female, will spend the majority of his time during the brief social encounter in anogenital inspection of the novel individual. If after $5 \mathrm{~min}$ the female is removed and replaced 30 min later by a new, novel female, WT mice will investigate the new female just as intensely as the first. OTKO males behave in an identical manner, with investigation times similar to WTs in both first and second exposures (Fig. 1a). There is no significant reduction in the duration of investigation during the second encounter for males of either genotype, as assessed by the Student's $t$ test for paired data $(p>0.05)$. There are also no significant genotype differences detected in the duration of investigation during either the first or second encounters, as assessed by the Student's $t$ test $(p>0.05)$.

If instead of using different females for each encounter, the first female is removed after $5 \mathrm{~min}$, placed into a holding cage for 30 min, and returned to the same male, WT mice show a significantly reduced level of olfactory investigation in the second encounter as compared with the first. The data are presented as RDI. The RDI was calculated by dividing the duration of investigation during the second encounter by the duration of investigation during the first. For WT males exposed to a familiar female, the mean RDI \pm $\mathrm{SEM}=0.38 \pm 0.03(p<0.05)$, indicating that the males recognize the previously encountered female as familiar. OTKO males do not show a significant decline in investigation of the female during the second exposure (RDI $=0.96 \pm 0.04$; NS) (Fig. 1b). During "same" female trials, there were no significant genotype differences in the duration of investigation during the first encounter, as assessed by a Student's $t$ test $(p>0.05)$.

A single intracerebroventricular injection of $1 \mathrm{ng}$ of OT given before the first social encounter restores social recognition in male OTKO mice (Ferguson et al., 2000). To determine whether $\mathrm{OT}$ is acting during the initial processing of the olfactory information or the consolidation or recall of the memory, OT treatment (1 ng, i.c.v.) was given either $10 \mathrm{~min}$ before or $10 \mathrm{~min}$ after the initial exposure and tested in the social recognition paradigm. There was an overall treatment effect as assessed by a one-way repeated measures ANOVA $\left(F_{(2,19)}=88.13 ; p<0.00001\right)$. Neither CSF $(\mathrm{RDI}=0.94 \pm 0.03$; NS), nor OT administered after social exposure $(\mathrm{RDI}=0.89 \pm 0.03$; NS) caused a significant decline in olfactory investigation during the second exposure. However, injections of OT before the first social encounter fully restored the recognition response $(\mathrm{RDI}=0.36 \pm 0.04 ; p<0.05)$.

\section{c-Fos immunocytochemistry}

To identify candidate sites for the OTKO mouse's deficit in the processing of olfactory cues during social encounters, we compared the neural activation patterns in OTKO and WT mice briefly exposed to a novel stimulus female using the protein product of the immediate early gene $c$-fos. There was no genotype
Figure 2. a, Neuroanatomical areas analyzed for Fos immunoreactivity after a social encounter. The boxes approximate the regions illustrated in Figures 3-6: accessory olfactory bulb $(A O B)$ and the granule cell layer of the main olfactory bulb $(O B)$; the dorsal portion of the lateral septum $(L S D)$; the bed nucleus of the stria terminalis $(B N S T)$; the medial preoptic area (MPOA); the somatosensory cortex (SS Ctx); the CA3 subregion of the hippocampus (CA3); the dentate gyrus $(D G)$; the medial nucleus of the amygdala $(M e A)$; the piriform cortex (Pir Ctx); and the cortical nucleus of the amygdala $(\mathrm{Co} A)$. Adapted from Paxinos and Watson (1998), Schematic illustrating the flow of olfactory information in the rodent brain (Meredith, 1991; Aggleton, 2001).

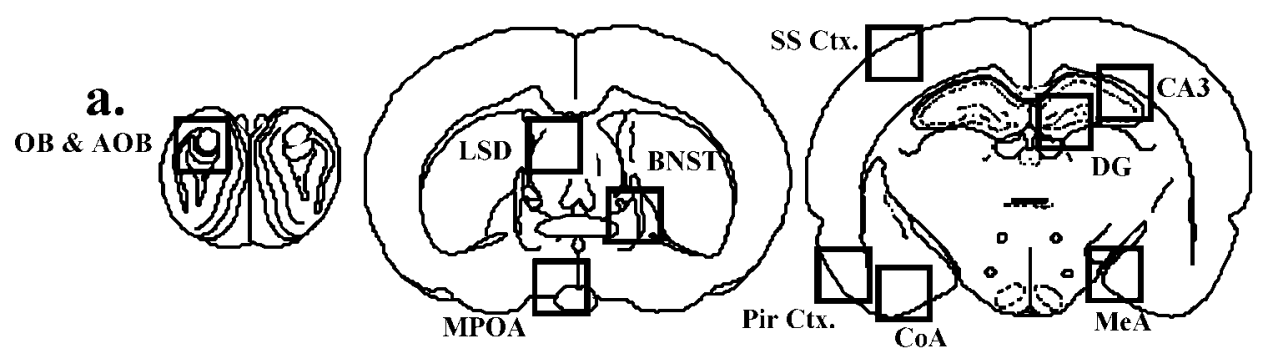

b.

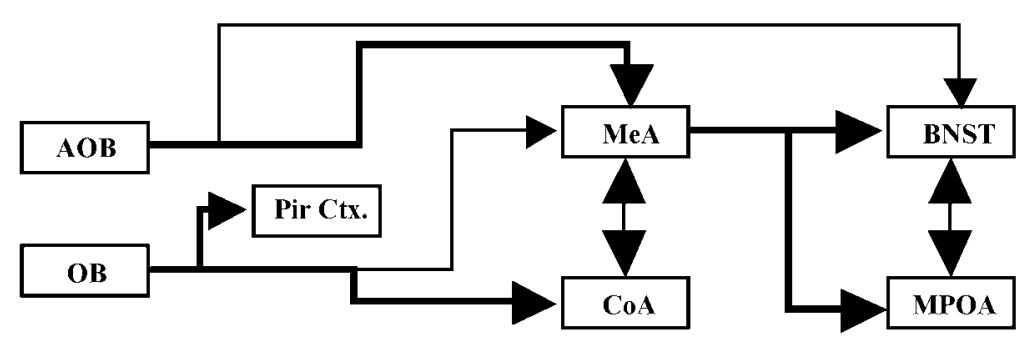




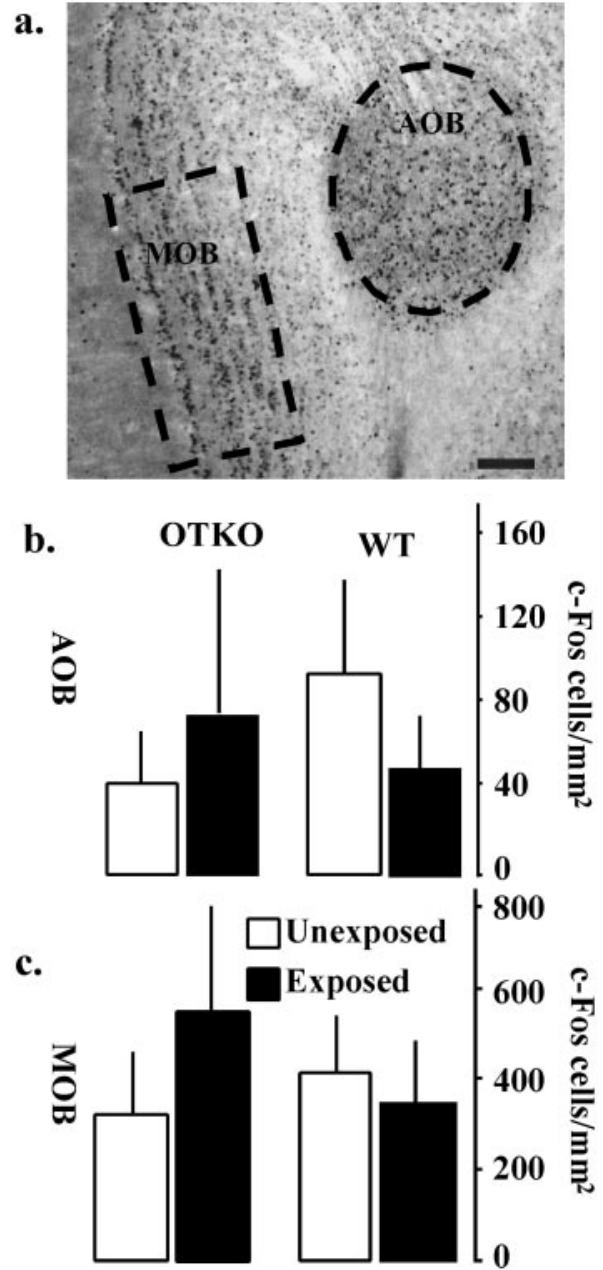

Figure 3. Neural activation in the main and accessory olfactory bulbs. $a$, c-Fos-immunoreactive cells in the $\mathrm{MOB}$ and the $\mathrm{AOB}$ of a representative OTKO male exposed to a stimulus female. Scale bar, $0.1 \mathrm{~mm}$. $b$, Summary data from the AOB. $c$, Summary data from the MOB. There were neither exposure nor genotype effects in either area. Each bar represents the mean number of c-Fos-positive cells per square millimeter \pm SEM calculated for each genotype and treatment condition.

difference in the amount of time spent engaged in olfactory investigation during this exposure $(p>0.05)$. After the $90 \mathrm{sec}$ interaction, the females were removed, and the males were left undisturbed in their home cages for $1 \mathrm{hr}$ before brain collection. Twelve additional animals were left undisturbed in their home cages until tissue collection. The brain regions analyzed for Fos-IR are illustrated in Figure $2 a$. A schematic illustrating the flow of olfactory information in the rodent brain is shown in Figure $2 b$. The main olfactory bulb (MOB) and the accessory olfactory bulb (AOB) exhibited similar densities of Fos-IR cells in the WT and OTKO mice and were not affected by exposure (Fig. 3, Table 1). There was a significant induction of Fos-IR in the lateral septum (LSD), the cortical nucleus of the amygdala (CoA), and the piriform cortex (Pir Ctx) in both WT and OTKO males after exposure but no genotype effects (Fig. 4, Table 1). In contrast, the MeA, the bed nucleus of the stria terminalis (BNST), and the medial preoptic area (MPOA) were significantly activated by the social encounter in WT but not OTKO males (Fig. 5, Table 1). In the somatosensory cortex (SS Ctx), and in $\mathrm{CA} 1, \mathrm{CA} 3$, and the dentate gyrus of the hippocampus, OTKO males showed a robust induction of Fos-IR after social exposure, whereas WT males showed no exposure-related activation (Fig. 6, Table 1).

\section{Site-specific injections}

The MeA, which failed to show an activation after a social exposure in the OTKO mice, receives olfactory input from the main and accessory olfactory bulb (Fig. $2 b$ ). Both the $\mathrm{OB}$ and $\mathrm{MeA}$ are rich in OT receptors (Insel et al., 1993). To determine the relative role of OT in these areas, site-specific OT infusions were performed in each area. First a dose-response curve was determined using doses of OT ranging from 0.1 to $1000 \mathrm{pg}$. A one-way repeated measures ANOVA detected a significant treatment effect $\left(F_{(5,36)}=8.51 ; p<0.0001\right)$, and Newman-Keuls post hoc tests revealed that doses of $\mathrm{OT} \geq 1 \mathrm{pg}$ effectively rescued the social recognition deficit (Fig. 7a). Therefore, 0.1 pg OT was used for the site-specific studies.

In OTKO males $(N=15)$ bilateral injections of OT, but not $\mathrm{CSF}$, into the MeA effectively restored species typical recognition responses. Neither OT nor CSF injected bilaterally into the OB rescued the deficit in social recognition (Fig $7 b$ ). To determine whether OT receptor activation in the MeA of WT males was necessary for social recognition, we injected $10 \mathrm{pg}$ of the selective OT receptor antagonist, ornithine vasotocin analog (OTA) into either the MeA or the $\mathrm{OB}$ before the initial exposure and tested the effects on social recognition. OTA prevented the normal decline in the duration of olfactory investigation when injected into the MeA of WT males, but was without effect when injected into the OB (Fig. 7c).

To assess the spread of the OT and OTA from the site of the injections, $0.5 \mu \mathrm{l}$ of India ink (right side) and ${ }^{125}$ I labeled OTA (left side) were injected into the OB and the MeA of all subjects. Examination of the radiolabeled OTA after injection revealed localization of the antagonist to the targeted areas (Fig. 8). In the olfactory bulb, ${ }^{125}$ I-labeled OTA was typically distributed throughout the granular and mitral cell layers in a pattern similar to the distribution of OT receptors (Insel et al., 1993).

\section{DISCUSSION}

We have previously reported that an OTKO mouse exhibits normal maternal care (Nishimori et al., 1996; Young et al., 1997) but has a selective deficit in social recognition (Ferguson et al., 2000). This deficit in social memory is notable because these mice show no impairment in other forms of memory, including the recall of nonsocial olfactory stimuli (Ferguson et al., 2000). In the present study, we demonstrated that OT infusions given before, but not after, the initial exposure restored social recognition. This result demonstrates that OT must be present during the initial exposure for social memories to form, suggesting that the deficit in social recognition in OTKO mice represents a defect in the initial processing of olfactory cues and not in the recall of the previously stored memory.

Analysis of the Fos-IR induction after a social exposure demonstrates similar neural activation in several brain regions involved in the processing of olfactory information, including the main OB, AOB, the Pir Ctx, and the CoA. However, the MeA, BnST, and MPOA show reduced activity during social experience in OTKO mice compared with WT mice. The MeA receives input from the main and accessory olfactory pathways and in turn projects to the BnST and MPOA (Fig. 2b) (Meredith, 1991; Aggleton, 2001). The pattern of neural activation in the OTKO mice, when compared with WT mice, suggests that olfactory 
Table 1. Statistical results of the c-Fos induction study

\begin{tabular}{llll} 
Area & Genotype & Exposure & Genotype $\times$ Exposure \\
\hline AOB & $\left(F_{(1,16)}=0.32\right)$ & $\left(F_{(1,16)}=0.49\right)$ & $\left(F_{(1,16)}=0.11\right)$ \\
MOB & $\left(F_{(1,16)}=0.45\right)$ & $\left(F_{(1,16)}=0.13\right)$ & $\left(F_{(1,16)}=0.08\right)$ \\
LSD & $\left(F_{(1,16)}=2.83\right)$ & $\left(F_{(1,16)}=9.27\right)$ & $\left(F_{(1,16)}=1.64\right)$ \\
CoA & $\left(F_{(1,16)}=1.01\right)$ & $\left(F_{(1,16)}=25.27\right)^{* * *}$ & $\left(F_{(1,16)}=2.76\right)$ \\
Pir Ctx & $\left(F_{(1,16)}=2.94\right)$ & $\left(F_{(1,16)}=30.14\right)^{* * *}$ & $\left(F_{(1,16)}=3.81\right)$ \\
MeA & $\left(F_{(1,16)}=7.11\right)^{*}$ & $\left(F_{(1,16)}=19.27\right)^{* *}$ & $\left(F_{(1,16)}=3.14 ; p=0.056\right)$ \\
BNST & $\left(F_{(1,16)}=4.74\right)^{*}$ & $\left(F_{(1,16)}=18.67\right)^{* *}$ & $\left(F_{(1,16)}=3.66 ; p=0.052\right)$ \\
MPOA & $\left(F_{(1,16)}=6.66\right)^{*}$ & $\left(F_{(1,16)}=21.00\right)^{* * *}$ & $\left(F_{(1,16)}=3.55 ; p=0.053\right)$ \\
DG & $\left(F_{(1,16)}=11.71\right)^{* *}$ & $\left(F_{(1,16)}=28.36\right)^{* * *}$ & $\left(F_{(1,16)}=17.43\right)^{* *}$ \\
CA3 & $\left(F_{(1,16)}=17.56\right)^{* *}$ & $\left(F_{(1,16)}=33.59\right)^{* * *}$ & $\left(F_{(1,16)}=19.59\right)^{* *}$ \\
SS Ctx & $\left(F_{(1,16)}=30.71\right)^{* * *}$ & $\left(F_{(1,16)}=31.93\right)^{* * *}$ & $\left(F_{(1,16)}=31.39\right)^{* * *}$
\end{tabular}

$* p<0.05$.

${ }^{* *} p<0.001$.

$* * * p<0.0001$.
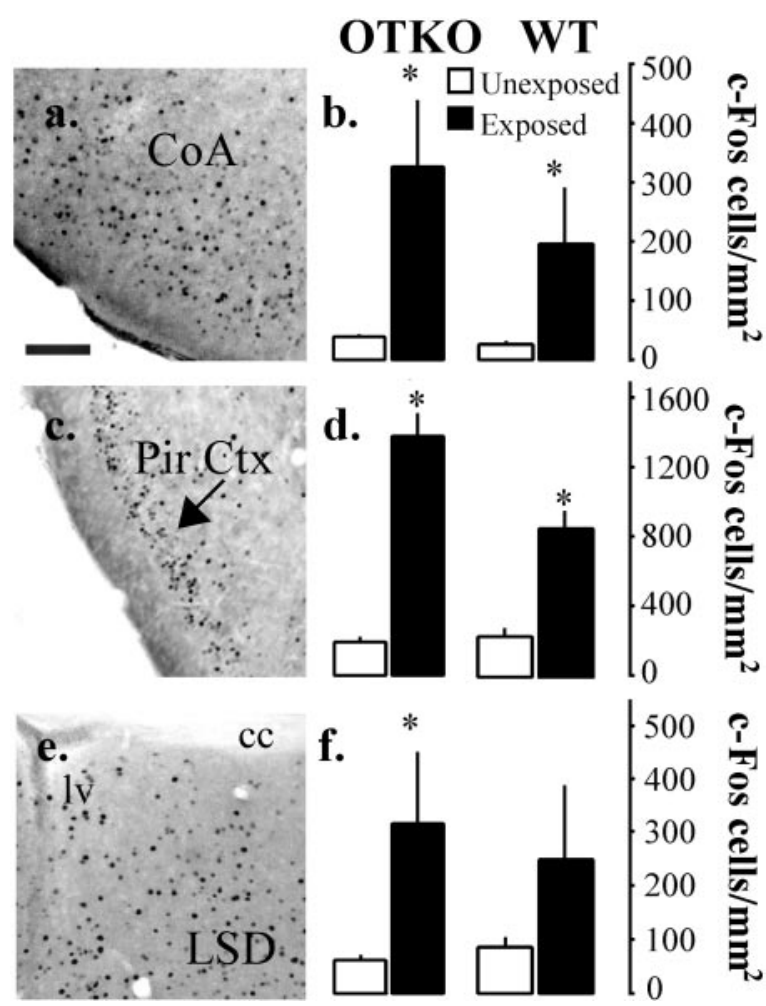

Figure 4. Neural activation after social encounter. Representative photomicrographs showing c-Fos-immunoreactive cells in the cortical amygdala $(C o A)(a)$, piriform cortex $(\operatorname{Pir} C t x)(c)$, and dorsal lateral septum $(L S D)(e)$. All images were taken from representative WT males. Scale bar, $0.1 \mathrm{~mm}$. Summary of data from the CoA $(b)$, Pir Ctx $(b)$, and the LSD $(f)$. Each bar represents the mean number of c-Fos-positive cells per square millimeter \pm SEM calculated for each genotype and treatment condition. In all cases, asterisks denote significant differences between exposed and unexposed animals of the same genotype, as assessed using the appropriate Newman-Keuls post hoc test $(p<0.05)$.

information is gathered and processed normally until it reaches the MeA, which fails to become activated. The incoming information is then not relayed on to the BNST or the MPOA. Injections of OT into the MeA, but not into the OB, rescued the recognition deficit in the OTKO mice. Similarly, OTA injected into the MeA (but not into the $\mathrm{OB}$ ) resulted in impaired social recognition in WT mice. Together, these results demonstrate that

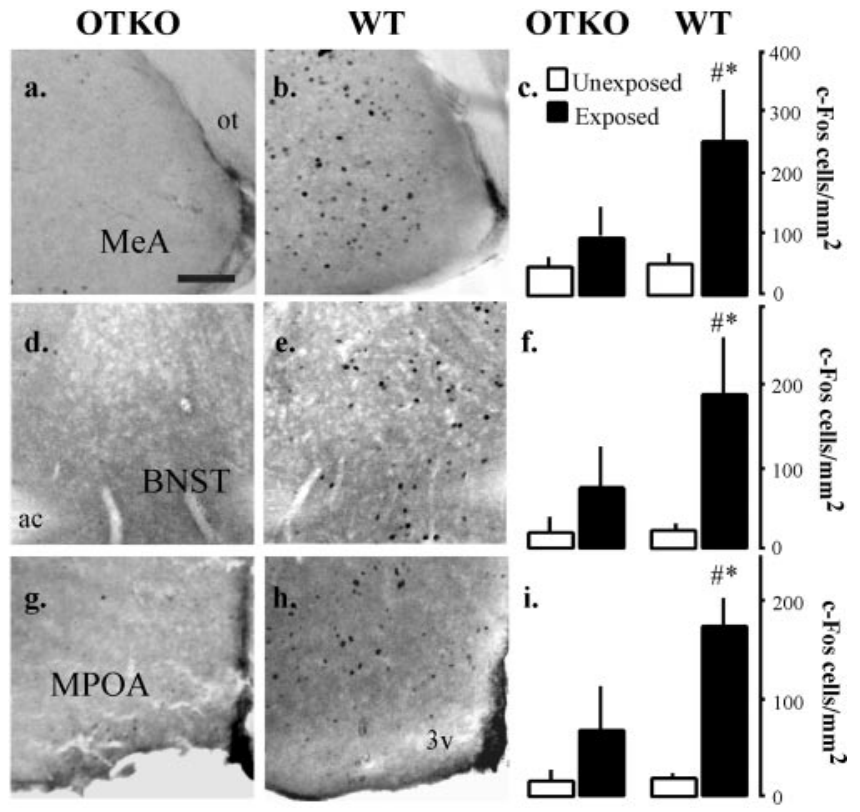

Figure 5. WT-specific patterns of neural activation. Representative photomicrographs showing c-Fos immunoreactivity in OTKO $(a, d, g)$ and $\mathrm{WT}(b, e, h)$ males in the medial amygdala $(M e A ; a, b)$, the bed nucleus of the stria terminalis $(B N S T ; d, e)$, and the medial preoptic area (MPOA; $g$, $h)$. Scale bar, $0.1 \mathrm{~mm}$. Summary of data from the MeA $(c)$, the BNST $(f)$, and the MPOA $(i)$. Each bar represents the mean number of c-Fospositive cells per square millimeter \pm SEM calculated for each genotype and treatment condition. In all cases, asterisks denote significant differences between exposed and unexposed animals of the same genotype, and pound signs denote significant genotype differences within the same exposure condition, as assessed using the appropriate Newman-Keuls post hoc tests $(p<0.05)$.

OT must be present in the MeA during the initial social exposure for the proper processing of the olfactory information and the development of the social memory.

The present results do not rule out a role for oxytocin in other brain regions, including the olfactory bulbs. In rats, low doses of OT injected both peripherally and ventricularly facilitate social recognition responses (Popik et al., 1992; Benelli et al., 1995). Previous studies have also demonstrated that in rats, OT administered site-specifically into the $\mathrm{OB}$ can prolong the species typical recognition response to $120 \mathrm{~min}$ and sometimes even longer 
OTKO

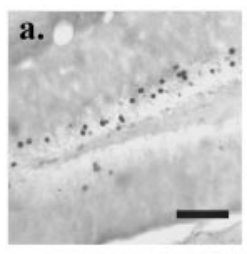

d.
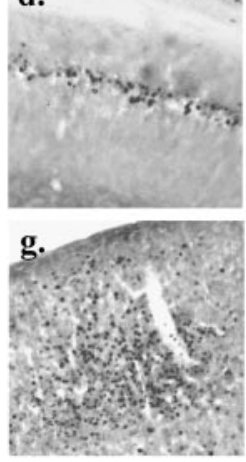

WT

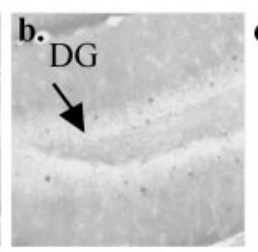

e.
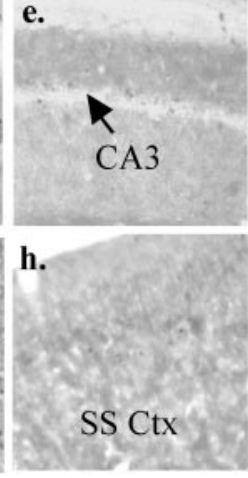

OTKO WT
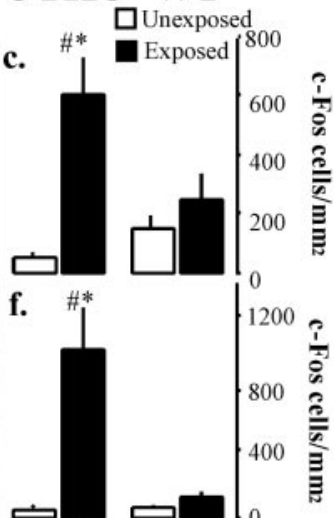

i.

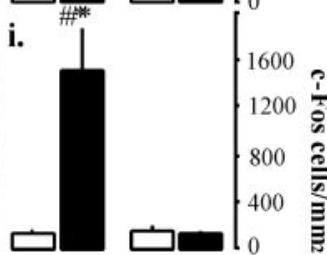

Figure 6. OTKO-specific patterns of neural activation. Representative photomicrographs showing c-Fos immunoreactivity in OTKO $(a, d, g)$ and WT $(b, e, h)$ males in the dentate gyrus $(D G ; a, b)$, CA3 cells of the hippocampus $(d, e)$, and somatosensory cortex $(S S C t x ; g, h)$. Scale bar, 0.1 $\mathrm{mm}$. Summary of data from the DG $(c), \mathrm{CA} 3(f)$, and SS Ctx $(i)$. Each bar represents the mean number of c-Fos-positive cells per square millimeter \pm SEM calculated for each genotype and treatment condition. In all cases, asterisks denote significant differences between exposed and unexposed animals of the same genotype, and pound signs denote significant genotype differences within the same exposure condition, as assessed using the appropriate Newman-Keuls post hoc tests $(p<0.05)$.

(Dluzen et al., 1998b). However, local infusions of OTA into the bulbs are ineffective in preventing the naturally occurring recognition response. It is therefore possible that $\mathrm{OT}$ in the $\mathrm{OB}$ is not necessary for recognition per se but instead is important for enhancing the species typical recall of socially relevant information. In fact, these data are consistent with distinct mechanisms underlying different components of social recognition and together with our current findings, raise the possibility that OT within the MeA is essential for the processing or initial retention of social information, whereas OT in the OBs and MPOA may modulate the maintenance or recall of that previously stored "trace"(Dluzen et al., 1998b).

Although the MeA has not previously been implicated in rodent social recognition, its involvement in this behavior is not surprising and has in fact been hypothesized by other investigators (Maaswinkel et al., 1996). In humans, the amygdala has consistently been implicated in the processing of faces, emotional expression, and social cues (Adolphs et al., 1994; Young et al., 1995; Scott et al., 1997). Studies looking at neural activation after nonsexual social encounters in rodents have also shown Fos induction in this nucleus, and also in its afferent and efferent connections (Fleming et al., 1994; Kirkpatrick et al., 1994; Wang et al., 1997; Greco et al., 1998). Known to be involved in the processing of pheromonal stimuli in golden hamsters (Petrulis and Johnston, 1999), the MeA has also been shown to be essential for a male vole's long-term ability to remember the olfactory signature associated with his mate (Demas et al., 1997). Across species, this area is theorized to be a site involved in the general integration of sensory information necessary for the regulation of

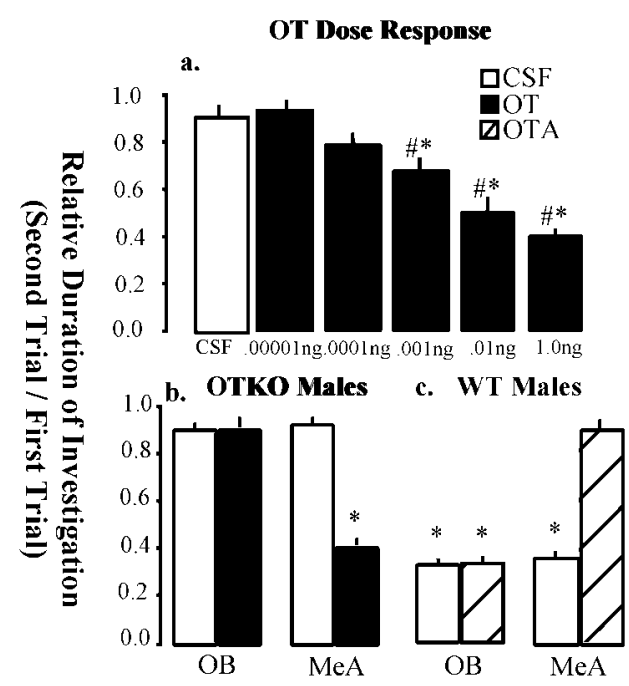

Figure 7. OT dose-response curve and site-specific injections of OT into the $\mathrm{OB}$ and MeA. $a$, Dose-response curve for intracerebroventricular OT rescue of social recognition in male OTKO mice. Bars represent the mean $\mathrm{RDI} \pm \mathrm{SEM}$ for each dose. A one-way repeated measures ANOVA detected a significant treatment effect $\left(F_{(5,36)}=8.51 ; p<0.0001\right)$, and Newman-Keuls post hoc tests revealed that several doses of OT differed significantly from CSF (denoted by pound signs). $b$, Site-specific injections of OT into the OB and MeA of OTKO mice. Subjects received injections of either CSF or $0.0001 \mathrm{ng}$ of OT into one of the two neuroanatomical areas, $10 \mathrm{~min}$ before the first social encounter, and were tested for social recognition. OT injected into the $\mathrm{MeA}$, but not the $\mathrm{OB}$ was effective in rescuing social recognition. $c$, Site-specific injections of oxytocin antagonist $(O T A)$ into the $\mathrm{OB}$ and MeA of WT mice. The WT males received injections of either CSF or $0.01 \mathrm{ng}$ OTA, $10 \mathrm{~min}$ before the first social encounter. In all cases, asterisks denote social recognition, or a significant decline in the duration of investigation during the second trial $(p<0.05)$.

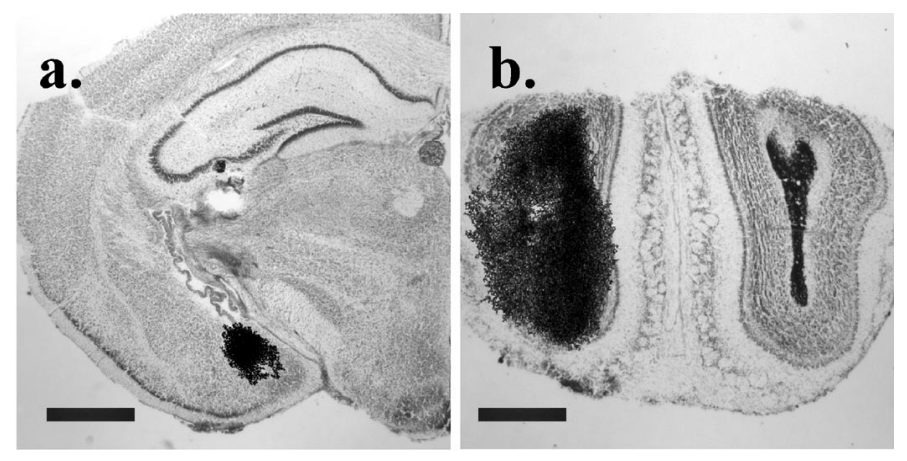

Figure 8. Cannula placement and ligand dispersion around the injection site. Cresyl violet-stained sections of the MeA $(a)$ and OB $(b)$ overlayed by aligned autoradiograms of adjacent sections, showing the spread of ${ }^{125} \mathrm{I}$-labeled OTA immediately surrounding the injection site. In the MeA, the OTA was typically confined to the MeA area without significant spread. In $b$ the animal was injected with ${ }^{25}$ I-labeled OTA in the left side and India ink on the right. Scale bars, $1.0 \mathrm{~mm}$.

social and sexual behaviors (Rasia-Filho et al., 2000). The major efferents of the MeA are to the BNST and the MPOA with minor projections to other limbic areas, including the lateral septum and the hippocampus, areas respectively implicated in a variety of social and mnemonic processes, including parental care, male sexual behavior, aggression, and territorial defense (Fleming et al., 1994; Kirkpatrick et al., 1994; Numan and Numan, 1994; Kollack-Walker and Newman, 1995; Lonstein et al., 1998).

The MeA is particularly rich in OT receptors in a variety of species, including the mouse (Insel et al., 1993). Although the 
mechanism through which OT modulates MeA activity is unknown, in other neuroanatomical areas, OT is believed to affect recognition responses by facilitating the release of other neurotransmitters (Levy et al., 1995; Dluzen et al., 1998a). Within the mouse OBs for example, OT facilitates noradrenergic release, thereby enhancing normal recognition responses through an $\alpha$-adrenergic-mediated mechanism (Brennan and Keverne, 1997; Dluzen et al., 2000). In the ewe, OT has also been demonstrated to stimulate the release of NA within both the MPOA and the $\mathrm{OB}$, where it facilitates behaviors associated with recognition and reduced aggression toward the lamb (Kendrick et al., 1992; Da Costa et al., 1996; Brennan and Keverne, 1997). The MeA of the mouse receives a significant noradrenergic projection and noradrenergic mechanisms are known to be involved in the long-term olfactory memories associated with pregnancy block in female mice (Rosser and Keverne, 1985; Brennan et al., 1995). Thus, it is possible that similar mechanisms may also be involved in the OT-dependent short-term recognition responses in the MeA of males.

In addition to the lack of Fos-IR activation in the MeA and its efferents, OTKO mice exhibited a massive overactivation in the SS Ctx and the hippocampus. It is unclear what the increased activity in the cortex and hippocampi of the OTKO animals might mean, but it is clear that a social memory does not form as a consequence of these atypical activations. Conceivably, this alternative pattern of activation could be the result of either a state of confusion or an attempt by the subjects to compensate for the deficits in the MeA system. Several recent imaging studies in human populations suggest that the recruitment of alternative neural pathways and sensory modalities might be represent a common strategy used in situations involving specific neural deficits (Drummond et al., 2000).

An interesting parallel with the present findings can be found in a series of recent neuroimaging studies in human autistic patients. When viewing images of faces, autistic subjects, compared with unaffected subjects, exhibit a decreased activation of both the amygdala and the cortical "face" areas, and interestingly, also show an increase in other cortical regions typically activated while viewing nonsocial objects (Critchley et al., 2000; Schultz et al., 2000). Other studies have found that autistic patients have an impaired recognition memory for faces, dramatically lowered levels of plasma OT concentrations, and neuropathology within the amygdala (Aylward et al., 1999; Baron-Cohen et al., 2000; Howard et al., 2000).

In summary, the deficit in social recognition in OTKO mice appears to be caused by inappropriate processing of socially relevant olfactory stimuli. Social and nonsocial olfactory cues are apparently processed differentially because OTKO mice habituate to nonsocial odors as rapidly as wild-type mice (Ferguson et al., 2000). This may be explained by the differential processing of pheromonal and non-pheromonal odorants or perhaps contextspecific processing of stimuli. In wild-type mice, oxytocin released in the MeA during a social encounter facilitates the formation of the social memory. In OTKO mice, the transmission of olfactory information appears normal up to, but not including the MeA. The MeA then fails to transmit this signal to the BNST and MPOA, regions that could also be involved in social recognition. As a consequence, alternative neural pathways are activated but do not compensate for the deficit. Many studies have demonstrated the involvement of OT in the regulation of complex social behaviors such as pair bond formation and parental care. Our results in addition demonstrate a critical role for OT in the early neural processing of simple social stimuli, essential for individual identification and recognition.

\section{REFERENCES}

Adolphs R, Tranel D, Damasio H, Damasio A (1994) Impaired recognition of emotion in facial expressions following bilateral damage to the human amygdala. Nature 372:669-672.

Aggleton JP (2001) The amygdala: a functional analysis, Ed 2. London: Oxford UP

Aylward EH, Minshew NJ, Goldstein G, Honeycutt NA, Augustine AM, Yates KO, Barta PE, Pearlson GD (1999) MRI volumes of amygdala and hippocampus in non-mentally retarded autistic adolescents and adults. Neurology 53:2145-2150.

Baron-Cohen S, Ring HA, Bullmore ET, Wheelwright S, Ashwin C, Williams SC (2000) The amygdala theory of autism. Neurosci Biobehav Rev 24:355-364.

Benelli A, Bertolini A, Poggioli R, Menozzi B, Basaglia R, Arletti R (1995) Polymodal dose-response curve for oxytocin in the social recognition test. Neuropeptides 28:251-255.

Brennan PA, Keverne EB (1997) Neural mechanisms of mammalian olfactory learning. Prog Neurobiol 51:457-481.

Brennan PA, Kendrick KM, Keverne EB (1995) Neurotransmitter release in the accessory olfactory bulb during and after the formation of an olfactory memory in mice. Neuroscience 69:1075-1086.

Carter CS, Williams JR, Witt DM, Insel TR (1992) Oxytocin and social bonding. Ann NY Acad Sci 652:204-211.

Critchley HD, Daly EM, Bullmore ET, Williams SC, Van Amelsvoort T, Robertson DM, Rowe A, Phillips M, McAlonan G, Howlin P, Murphy DG (2000) The functional neuroanatomy of social behaviour: changes in cerebral blood flow when people with autistic disorder process facial expressions. Brain 123:2203-2212.

Da Costa AP, Guevara-Guzman RG, Ohkura S, Goode JA, Kendrick KM (1996) The role of oxytocin release in the paraventricular nucleus in the control of maternal behaviour in the sheep. J Neuroendocrinol 8:163-177.

Dantzer R, Bluthe RM, Koob GF, Le Moal M (1987) Modulation of social memory in male rats by neurohypophyseal peptides. Psychopharmacology 91:363-368.

Demas GE, Williams JM, Nelson RJ (1997) Amygdala but not hippocampal lesions impair olfactory memory for mate in prairie voles (Microtus ochrogaster). Am J Physiol 273:R1683-R1689.

Dluzen DE, Muraoka S, Landgraf R (1998a) Olfactory bulb norepinephrine depletion abolishes vasopressin and oxytocin preservation of social recognition responses in rats. Neurosci Lett 254:161-164.

Dluzen DE, Muraoka S, Engelmann M, Landgraf R (1998b) The effects of infusion of arginine vasopressin, oxytocin, or their antagonists into the olfactory bulb upon social recognition responses in male rats. Peptides 19:999-1005.

Dluzen DE, Muraoka S, Engelmann M, Ebner K, Landgraf R (2000) Oxytocin induces preservation of social recognition in male rats by activating alpha-adrenoceptors of the olfactory bulb. Eur J Neurosci 12:760-766.

Drummond SP, Brown GG, Gillin JC, Stricker JL, Wong EC, Buxton RB (2000) Altered brain response to verbal learning following sleep deprivation. Nature 403:655-657.

Ferguson JN, Young LJ, Hearn EF, Matzuk MM, Insel TR, Winslow JT (2000) Social amnesia in mice lacking the oxytocin gene. Nat Genet 25:284-288

Fleming AS, Suh EJ, Korsmit M, Rusak B (1994) Activation of Fos-like immunoreactivity in the medial preoptic area and limbic structures by maternal and social interactions in rats. Behav Neurosci 108:724-734.

Gheusi G, Bluthe R-M, Goodall G, Dantzer R (1994) Social and individual recognition in rodents: methodological aspects and neurobiological bases. Behav Proc 33:59-87.

Greco B, Edwards DA, Zumpe D, Michael RP, Clancy AN (1998) Fos induced by mating or noncontact sociosexual interaction is colocalized with androgen receptors in neurons within the forebrain, midbrain, and lumbosacral spinal cord of male rats. Horm Behav 33:125-138.

Howard MA, Cowell PE, Boucher J, Broks P, Mayes A, Farrant A Roberts N (2000) Convergent neuroanatomical and behavioural evidence of an amygdala hypothesis of autism. NeuroReport 11:2931-2935.

Insel TR (1992) Oxytocin-a neuropeptide for affiliation: evidence from behavioral, receptor autoradiographic, and comparative studies. Psychoneuroendocrinology 17:3-35.

Insel TR (1997) A neurobiological basis of social attachment. Am J Psychiatry 154:726-735.

Insel TR, Young L, Witt DM, Crews D (1993) Gonadal steroids have paradoxical effects on brain oxytocin receptors. J Neuroendocrinol 5:619-628.

Kaba H, Rosser A, Keverne B (1989) Neural basis of olfactory memory in the context of pregnancy block. Neuroscience 32:657-662.

Kendrick KM, Keverne EB, Hinton MR, Goode JA (1992) Oxytocin, 
amino acid and monoamine release in the region of the medial preoptic area and bed nucleus of the stria terminalis of the sheep during parturition and suckling. Brain Res 569:199-209.

Keverne EB (1998) Vomeronasal/accessory olfactory system and pheromonal recognition. Chem Senses 23:491-494.

Keverne EB, Kendrick KM (1992) Oxytocin facilitation of maternal behavior in sheep. Ann NY Acad Sci 652:83-101.

Kirkpatrick B, Kim JW, Insel TR (1994) Limbic system fos expression associated with paternal behavior. Brain Res 658:112-118.

Kollack-Walker S, Newman SW (1995) Mating and agonistic behavior produce different patterns of Fos immunolabeling in the male Syrian hamster brain. Neuroscience 66:721-736.

Levy F, Kendrick KM, Goode JA, Guevara-Guzman R, Keverne EB (1995) Oxytocin and vasopressin release in the olfactory bulb of parturient ewes: changes with maternal experience and effects on acetylcholine, gamma-aminobutyric acid, glutamate and noradrenaline release. Brain Res 669:197-206.

Lonstein JS, Simmons DA, Swann JM, Stern JM (1998) Forebrain expression of c-fos due to active maternal behaviour in lactating rats. Neuroscience 82:267-281.

Maaswinkel H, Baars AM, Gispen WH, Spruijt BM (1996) Roles of the basolateral amygdala and hippocampus in social recognition in rats. Physiol Behav 60:55-63.

Meredith M (1991) Sensory processing in the main and accessory olfactory systems: comparisons and contrasts. J Steroid Biochem Mol Biol 39:601-614.

Nishimori K, Young LJ, Guo Q, Wang Z, Insel TR, Matzuk MM (1996) Oxytocin is required for nursing but is not essential for parturition or reproductive behavior. Proc Natl Acad Sci USA 93:11699-11704.

Numan M, Numan MJ (1994) Expression of Fos-like immunoreactivity in the preoptic area of maternally behaving virgin and postpartum rats. Behav Neurosci 108:379-394.

Paxinos G, Watson C (1998) The rat brain in stereotaxic coordinates, Ed 3. San Diego: Academic.

Perio A, Terranova JP, Worms P, Bluthe RM, Dantzer R, Biziere K (1989) Specific modulation of social memory in rats by cholinomimetic and nootropic drugs, by benzodiazepine inverse agonists, but not by psychostimulants. Psychopharmacology 97:262-268.
Petrulis A, Johnston RE (1999) Lesions centered on the medial amygdala impair scent-marking and sex-odor recognition but spare discrimination of individual odors in female golden hamsters. Behav Neurosci 113:345-357.

Popik P, van Ree JM (1998) Neurohypophyseal peptides and social recognition in rats. Prog Brain Res 119:415-436.

Popik P, Vetulani J, van Ree JM (1992) Low doses of oxytocin facilitate social recognition in rats. Psychopharmacology 106:71-74.

Rasia-Filho AA, Londero RG, Achaval M (2000) Functional activities of the amygdala: an overview. J Psychiatry Neurosci 25:14-23.

Rosser AE, Keverne EB (1985) The importance of central noradrenergic neurones in the formation of an olfactory memory in the prevention of pregnancy block. Neuroscience 15:1141-1147.

Schultz RT, Gauthier I, Klin A, Fulbright RK, Anderson AW, Volkmar F, Skudlarski P, Lacadie C, Cohen DJ, Gore JC (2000) Abnormal ventral temporal cortical activity during face discrimination among individuals with autism and Asperger syndrome. Arch Gen Psychiatry 57:331-340.

Scott SK, Young AW, Calder AJ, Hellawell DJ, Aggleton JP, Johnson M (1997) Impaired auditory recognition of fear and anger following bilateral amygdala lesions. Nature 385:254-257.

Thor DH, Holloway WR (1981) Persistence of social investigatory behavior in the male rat: Evidence for long-term memory of initial copulatory experience. Anim Learn Behav 9:561-565.

Thor DH, Holloway WR (1982) Social memory of the male laboratory rat. J Comp Psychol 96:1000-1006.

Wang Z, Hulihan TJ, Insel TR (1997) Sexual and social experience is associated with different patterns of behavior and neural activation in male prairie voles. Brain Res 767:321-332.

Winslow JT, Camacho F (1995) Cholinergic modulation of a decrement in social investigation following repeated contacts between mice. Psychopharmacology (Berl) 121:164-172.

Young AW, Aggleton JP, Hellawell DJ, Johnson M, Broks P, Hanley JR (1995) Face processing impairments after amygdalotomy. Brain 118:15-24.

Young LJ, Winslow JT, Wang Z, Gingrich B, Guo Q, Matzuk MM, Insel TR (1997) Gene targeting approaches to neuroendocrinology: oxytocin, maternal behavior, and affiliation. Horm Behav 31:221-231. 